\title{
SER CRIVADO DE RAÇAS, CULTURAS E REALIDADES: O VOLKSGEIST NO BRASIL
}

Marcelo Chiaretto*

RESUMO:

Este ensaio pretende estabelecer um estudo comparativo entre as teorias nacionalistas românticas verificadas no séc. XIX, levando em consideração sobretudo seus reflexos sobre 0 movimento nacionalista brasileiro.

PALAVRAS-CHAVE: literatura alemã, francesa e brasileira, romantismo, nacionalismo.

Não ser selvagem! Que sou eu senão um selvagem, ligeiramente polido, com uma tênue camada de verniz por fora? Quatrocentos anos de civilização, outras raças, outros costumes, e eu disse que não sabia o que se passava na alma de um caeté! Provavelmente o que se passa na minha, com algumas diferenças. Um caeté de olhos azuis, que fala português ruim, sabe escrituração mercantil, lê jornais, ouve missas. É isto, um caeté.

Graciliano Ramos

Pode-se dizer que estudar o romantismo nacionalista do Brasil principalmente no que tange ao indianismo - implica a abordagem dos efervescentes anos de fundação da literatura brasileira. São aqueles tempos capazes de terem fomentado um intenso debate que tornou enfáticos tanto as tentativas de definir a cor local quanto os primeiros esforços de constituição da história literária no país. Tais esforços e tentativas, de forma até previsível, geraram estudos que acabaram obviamente por indiciar a sua participação no processo de formação nacional, uma formação da mesma forma divergente e problemática ao se considerarem os vários "perfis" e as múltiplas "identidades" possíveis para a nação.

Para a elaboração deste ensaio, convém dizer que o campo mais instigante não é somente o que ora se destaca, referente ao nacionalismo exclusivo do primeiro romantismo brasileiro (a fase indianista, aproximadamente de 1836 a 1850). Neste, * Doutor em Letras: Estudos Literários (Área de concentração: Literatura Comparada), 2000. 


\section{EM TESE}

Belo Horizonte, v. 5, p. I-305, dez. 2002

causa também grande interesse a possibilidade de se perceber o aproveitamento - em uma perspectiva, a bem dizer, politicamente transformadora - das concepções nacionalistas do pré-romantismo alemão (datadas aproximadamente de fins do séc. XVIII) - caracterizado no movimento denominado Sturm und Drang (em possível tradução, pode-se entender Tempestade e İmpeto).

Sobre este movimento, o que primeiramente gera impressão é o seu caráter de resistência contra a importação da cultura francesa para os reinados alemães e contra o poder político homogeneizador sob a égide do Estado moderno. Como reação, firmou-se um impulso em defesa da existência das várias culturas e suas tradições, um ímpeto a favor do direito nacional à autodeterminação e à liberdade coletiva.

Acresce dizer que as noções deste movimento foram baseadas na obra do alemão J. G. Herder. Este, ao elaborar um pensamento que se colocava como uma alternativa às idéias iluministas de Voltaire, logrou determinar as bases do que seria o nacionalismo - principalmente o literário - do século XIX. Dessa maneira, o pensador alemão estabeleceria uma concepção de nação em que esta firmar-se-ia de acordo com a sua história particular, com seu caráter ou, melhor dizendo, de acordo com seu Volksgeist - o "espírito da nação", a "alma do povo", a "inteligência popular" (dentre outras possíveis traduções), em si a porção imaginada como mais genuína para representar a nacionalidade. Essa mística "construção" seria lograda tendo em vista a ênfase na participação popular, depreendendo-se daí que as decisões nacionais seriam tomadas por manifestações geradas "de baixo para cima", invertendose assim a lógica aristocrática. A concretização desse ideal, é bom destacar, passaria então a freqüentar as imaginações de escritores, poetas e historiadores onde quer que houvesse algum sentimento arraigado de diferença nacional.

De fato, uma certa produção literária influenciada pelas palavras de Herder (como foi no Sturm und Drang) firmaria como objetivo precípuo incitar as emoções das classes populares e as imaginações poéticas com vistas à expressão do Gênio Nacional (ou dos Gênios Nacionais), salientando a diferença cultural básica existente entre as várias nações. Dessa maneira, haveria por um lado uma contraposição a uma literatura erudita inatingível às classes populares, assim como a uma produção literária a reproduzir de forma submissa o gosto moderno baseado em deslocados 
francesismos. Também, por outro lado, surgiria uma produção atenta às raízes primitivas da nacionalidade, expressas na ancestralidade dos povos em seus hábitos, raças e costumes característicos.

Tais idéias, em combinação com outras obviamente, foram responsáveis pela detonação do nacionalismo romântico, a partir da Alemanha (ou dos "reinados alemães") para a Europa, da Europa indefinidamente a outras terras. Nesse trânsito de perspectivas, seriam assim conformadas ambições que tendiam por um caráter nacional próprio contra uma moderna cultura das luzes, que acabava fatalmente por se impor como modelo padronizador de comportamento, de instituição e de valores.

No Brasil haveria, por sua vez, um movimento romântico a evidenciar o elemento indígena no papel de símbolo do Gênio Nacional, responsável pela expressão primitiva do novo Estado. A ênfase em tal elemento, por seu lado, tenderia a ser vista como um esforço pela exaltação do Volksgeist brasileiro. Entretanto, no papel de orientador e promotor deste processo de re-caracterização de um território recém-independente, não se vê objetivamente ou de forma claramente explícita o alemão Herder em sua teoria nacionalista, mas, sim, a atuação preponderante de um francês consciente dessa teoria, Ferdinand Denis, bem como de um interessado grupo de nacionalistas românticos brasileiros que a este seguiam.

Para melhor compreensão, é relevante apontar que os românticos indianistas no Brasil demonstravam entender objetivamente a grande contribuição trazida pelas noções nacionalistas vindas do exterior. A priori, vale realçar que a teoria romântico-alemã de Herder e A. Schlegel é citada em primeira ou segunda mão por um significativo grupo dentre os críticos mais importantes do romantismo indianista brasileiro. A partir de tal teoria, foi lograda uma diferenciação nacional, tendo em vista a diferenciação estética alcançada sob um clima de forte aversão a toda determinação da metrópole. Além disso, havia a noção germânica de Volksgeist, algo próprio para conformar uma monitorada idéia de inteligência nacional popular, forjada em "honra, respeito e orgulho" a todo traço autóctone. Diante dessas idéias, o modelo de civilização europeu foi de certa maneira relativizado, já que se estabeleceu, ao menos de forma teórica, um espaço eclético para a vida de outras culturas.

Para o Brasil, tal relativização evidenciou uma possível oportunidade de se instaurar uma diferença, ou melhor, um caráter mais próximo de sua civilização 


\section{EM TESE}

Belo Horizonte, v. 5, p. I-305, dez. 2002

e de seus habitantes. Os entraves a serem superados para que os intelectuais introduzissem aqui tais concepções relativizadoras eram todavia bem consideráveis. 0 denominado povo brasileiro na época não tinha vida política, em outras palavras, estava fora de qualquer contato institucional. Além disso, as estreitas relações mantidas entre os intelectuais e a elite detentora do poder estabelecia um ambiente refratário às opiniões adversas. Daí, a literatura de valorização do nacional no romantismo acabou por se tornar parte da ideologia oficial, o que gerou um Volksgeist brasileiro menos mítico, menos inconformado com o poder estabelecido e menos resistente diante das influências estrangeiras, por exemplo.

Pelo contrário, pode-se mencionar que o espírito nacional no Brasil foi firmado com a intenção principal de celebrar o consenso. Seria algo pouco condizente com o modelo alemão, mas coerente com uma terra "sem povo" e de população composta por tantos e tão variados grupos, a viver alienados do Estado e sob o risco dos contatos menos amistosos sempre muito próximos. Tornou-se fundamental assim uma voz de autoridade, que poderia vir tanto do governo imperial quanto dos intelectuais, mas que porém fosse capaz de dar existência e comando a esse projecional povo brasileiro. Com essa atitude, a espontaneidade da população e suas emoções coletivas seriam sacrificadas em vista da criação de uma voz popular pronta para corroborar os sonhos nacionais românticos.

0 fascínio nacional, sendo no Brasil (assim como em grande parte dos países) de ascendência teórica germânica, teve o dever no entanto de rechaçar o particularismo reacionário. Da mesma forma, teve que evitar a exaltação de uma cultura isolacionista imprópria para um país que busca ter estilo específico ao mesmo tempo que o prestígio das nações mais importantes. Assim, para enobrecer as tradições autóctones afigurou-se relevante uma exploração da primitiva cultura indígena, mas de forma a que a realidade fosse próxima dos admirados niebelungen ou dos heróicos cavaleiros medievais à moda de Ossian, que honravam a origem dos grandes povos. 0 índio brasileiro tornou-se assim uma ficção, uma vez que sua realidade parecia aos intelectuais pouco destacável.

$\mathrm{Na}$ conformação desse índio, pode-se ver por sua vez a indispensável contribuição francesa, cuja concepção imaginária do Bom Selvagem apresentava certas 
coincidências com o ser na maneira primitiva do Brasil. Vinculando-se o Brasil com essa noção tão íntima e ao mesmo tempo tão afamada, foi assim logrado um espaço para a revelação da terra como local do exótico paradisíaco, um campo para a recreação do imaginário europeu sem a devida correspondência com a realidade (que já era obscurecida pelos próprios românticos brasileiros).

A propósito, a contribuição francesa seria importante também para a resolução de um outro problema: com o fim de se administrar o entusiasmo advindo do tão exaltado Volksgeist brasileiro, verificou-se a necessidade de uma disciplina, ou melhor, de uma literatura pacificadora preocupada com a educação moral e cívica, tendo em vista a presença entre a população de conflitos, hábitos e tradições locais indignos de um país que anseia a civilização moderna. Assim, conforma-se a situação em que o Volksgeist no Brasil ganha novos contornos da cultura francesa, algo muito conveniente, uma vez que naquele período a França determinava mundialmente o modelo de cultura, além de expor uma literatura instrutiva calcada no uso da natureza tropical. É o momento em que se firma junto aos brasileiros o relevante papel do pré-romantismo francês, de acordo com Madame de Staël, Bernardin de Saint-Pierre e Chateaubriand, dando dicas de como exaltar o índio, de como descrever a natureza e, principalmente, de como plasmar uma nova civilização, cristã, branca, consensual e disciplinada, capaz de fundar uma nação autônoma e popular conforme a visão germânica, mas dentro dos parâmetros evidenciados pelo modelo ocidental.

Não há assim embaraço em se observar o conceito de Volksgeist sendo aplicado no Brasi1. Convém mencionar, no entanto, que sua aplicação ocorreu de forma a não respeitar o que seria de fato identitário no país. Em outras palavras, foi defendida uma mística indígena e, mais importante, uma mística populista em desacordo com a realidade nacional brasileira, mas em harmonia com a necessidade européia de ver aqui um povo jovem, pacífico, entusiasmado e amante da natureza se assumindo como retrato do Brasil "para exportação". Além disso, nota-se dentre as idéias dos autores franceses a defesa de um modelo homogeneizado de civilização, que não se solidariza com o modelo civilizatório de Herder (o mais destacado teórico da noção de Volksgeist) e, conseqüentemente, com o romantismo nacionalista pluricultural que tem em Herder o seu inspirador. Na realidade, pode-se afirmar que tais românticos franceses tornaram o modelo nacional "germânico" - e sua concepção de Volksgeist - 


\section{EM TESE}

Belo Horizonte, v. 5, p. I-305, dez. 2002

menos culturalmente relativizado, mais universalista e mais "europeu", ou seja, mais contíguo a uma cultura francesa hegemônica.

Tais deduções logo tornariam adequada a eleição, por parte dos intelectuais indianistas brasileiros, do francês Ferdinand Denis (o grande responsável pela difusão no país das idéias do pré-romantismo francês) como líder e fonte inspiradora do romantismo nacionalista no Brasil. No entanto, verifica-se que esses intelectuais logram em um certo momento um desenvolvimento bem interessante das noções desse estudioso francês. Baseados neste e em um pensamento "alemão" de ênfase no relativismo calcado em Herder, eles chegam a promover uma forma identitária para o Brasil menos ao gosto europeu e mais coerente com uma diferença fundante, ou melhor, em harmonia com um país crivado por raças, culturas e realidades.

É então o momento de observar o trajeto teórico percorrido pelos românticos no Brasil. Grosso modo, tal trajeto iria de A. W. Schlegel - com sua teoria romântica populista e relativizadora calcada no nacionalismo herderiano - até Chateaubriand, Bernardin de Saint-Pierre e Madame de Staël. Estes, por sua vez, seriam os escritores que teriam determinado o estudioso francês Denis em suas noções marcadamente afins ao ideal europeu de modernidade, tendo em vista a expansão da civilização ocidental para os países de civilização "nascente", como o Brasil.

A partir daí, é possível assim perceber atentamente os reflexos da ascendência européia sobre as estratégias literato-nacionalistas do primeiro romantismo brasileiro, o indianista, bem como notar os momentos em que tal ascendência é redimensionada com vistas a um Gênio nacional mais assumidamente brasileiro. É importante ver aí sobretudo o estreito contato com a literatura nacionalista alemã. Dentre todos os românticos brasileiros dessa fase, Gonçalves Dias pode ser encarado como o que melhor segue tal caminho: se os outros autores indicavam em seus textos epígrafes e curiosas referências textuais aos literatos alemães do Sturm und Drang, Dias foi o único a lê-los em alemão, além de ser o único a expor a tradução de um poema de Herder ${ }^{1}$. Gonçalves Dias, principalmente, apresentou uma visão particularizada do índio, que evitava a mestiçagem por temer o fim de sua diferença cultural, o que o colocava em situação de comunicabilidade com as idéias de Herder e de contraste mesmo com José de Alencar. Do mesmo modo, é relevante explicitar a presença dos 
românticos alemães na obra crítico-nacionalista desse mesmo romantismo indianista. Causa de fato impressão então quando se descobre, por exemplo, em um estudo de Joaquim Norberto de Sousa Silva² - um crítico cuja contribuição à literatura brasileira do séc. XIX é fundamental -, uma citação de Herder em que este expõe 0 presente como espaço para a explicação do passado, como espaço para a instauração de um arquivo que fosse espelho da espontaneidade do povo.

Em todas essas delineadas explorações, é preciso salientar que a meta é de não simplesmente frisar uma suposta continuidade de idéias, mas enfatizar a transmissão e a comunicação de conceitos e concepções, a partir de então transformados e diferenciados. 0 ponto de vista firmado opta por adotar um método que seja simultaneamente histórico e estético, através do qual se firma um esforço por observar, por exemplo, determinadas formulações nacionais e seus efeitos sobre a vida cultural do público (dado histórico-cultural), assim como as obras que melhor expressam a literatura como campo de expressão imaginária do que seria de fato nacional ou representativo de uma certa coletividade (dado estético-literário).

Tais considerações, na realidade, são relevantes quando se percebe 0 caráter pragmático de grande parte da produção literária romântica do início do século XIX. Sabe-se que, neste período, declinou-se do aspecto estético muitas vezes em vista da necessidade de uma produção literária francamente engajada. Para um Estado formado, porém de incipiente consciência do que seria autonomia ou unidade nacional, compreende-se a urgência brasileira de uma literatura "interessada", crente na sua função de criar vínculos nacionais, mesmo ao preço de "os escritores se sentirem freqüentemente tolhidos no vôo, prejudicados no exercício da fantasia pelo peso do sentimento de missão"3.

De fato, parece claro que um estudo de literatura deve evidenciar a literatura não como produto de uma realidade histórica, inserida em um discurso documental ou nacional que buscaria instrumentalizá-la ou aprisioná-la em fronteiras geográficas, deixando de lado as especificidades de ordem política e cultural. Em contraposição, é indispensável contemplá-la como elemento constituinte e atuante dentro de uma conjuntura social. Nessa perspectiva, pode-se assim evitar uma visão da História provida de uma deliberada ambição totalizante em favor de uma visão da história - ou das histórias - como manifestações de povos desierarquizados e heterogêneos. 


\section{EM TESE}

Belo Horizonte, v. 5, p. I-305, dez. 2002

NOTAS:

1. Gonçalves Dias, 1954. p. 201.

2. SILVA, J. N. S. Mosaico poético. In: ZILBERMAN (Org.), 1998. p. 191.

3. Cf. Candido, 1993: Tomo I, p. 26.

RÉSUMÉ :

Ce travail essaye d'établir une étude comparative entre les théories nationalistes romantiques verifiées dans le siècle XIX, en considérant de plus les reflets au mouvement nationaliste brésilien.

MOTS-CLÉS: littérature allemande, française et brésilienne, romantisme, nationalisme.

CANDID0, Antonio. Formação da literatura brasileira. 2 v. 7. ed. Belo Horizonte: Itatiaia, 1993.

FALBEL, Nachman. Os fundamentos históricos do romantismo. In: Guinsburg, J. (Org.) 0 romantismo. São Paulo: Perspectiva, 1993.

GONÇALVES DIAS, Antônio. Cantos. In: Grandes poetas românticos do Brasil. São Paulo: Ed. LEP, 1954 (do original).

HERDER, J. G. Também uma filosofia da história para a formação da humanidade. Trad. José M. Justo. Lisboa: Antígona, 1995.

LACQUE-LABARTJE, P.; NANCY, J. L. L'absolu littéraire. Paris: Seuil, 1978.

LOWY, Michael \& SAYRE, Robert. Revolta e melancolia: o romantismo na contramão da modernidade. Trad. Guilherme F. Teixeira. Petrópolis: Vozes, 1995.

ROUANET, Maria Helena. Eternamente em berço esplêndido: a fundação de uma literatura nacional. São Paulo: Siciliano, 1991.

VAN TIEGHEM, Philippe. Histoire de la littérature française. Paris: Librairie Arthème Fayard, 1949.

- Le Préromantisme. Études d'histoire littéraire européenne. 3 vol, [s.1.]: Sfelt, 1924-1948.

ZILBERMAN, R. O berço do cânone: textos fundadores da história da literatura brasileira. Porto Alegre: Mercado Aberto, 1998. 